\title{
Opportunities and challenges in using remaining carbon budgets to guide climate policy
}

\section{Published: https://www.nature.com/articles/s41561-020-00663-3}

H. Damon Matthews ${ }^{1 *}$, Katarzyna B. Tokarska ${ }^{2}$, Zebedee R. J. Nicholls ${ }^{3,4}$, Joeri Rogelj ${ }^{5,6}$, Josep G. Canadell ${ }^{7}$, Pierre Friedlingstein ${ }^{8,9}$, Thomas L. Frölicher ${ }^{10,11}$, Piers M. Forster ${ }^{12}$, Nathan P. Gillett $^{13}$, Tatiana Ilyina ${ }^{14}$, Robert B. Jackson ${ }^{15}$, Chris D. Jones ${ }^{16}$, Charles Koven ${ }^{17}$, Reto Knutti ${ }^{2}$, Andrew H. MacDougall ${ }^{18}$, Malte Meinshausen ${ }^{3}$, Nadine Mengis ${ }^{19,20}$, Roland Séférian ${ }^{21}$, and Kirsten Zickfeld ${ }^{20}$

${ }^{1}$ Department of Geography, Planning and Environment, Concordia University, Montréal, Canada

${ }^{2}$ Institute for Atmospheric and Climate Science, ETH Zürich, Zürich, Switzerland

${ }^{3}$ Australian-German Climate and Energy College, The University of Melbourne, Parkville, Victoria, Australia

${ }^{4}$ School of Earth Sciences, The University of Melbourne, Parkville, Victoria, Australia

${ }^{5}$ Grantham Institute, Imperial College London, UK

${ }^{6}$ International Institute for Applied Systems Analysis (IIASA), Laxenburg, Austria

${ }^{7}$ Global Carbon Project, CSIRO Oceans and Atmosphere, Canberra, ACT, Australia

${ }^{8}$ College of Engineering, Mathematics and Physical Sciences, University of Exeter, UK

${ }^{9}$ Laboratoire de Météorologie Dynamique, Département de géosciences, École Normale Supérieure, PSL Research University, Sorbonne Université, École polytechnique, CNRS, F-75005 Paris, France

${ }^{10}$ Climate and Environmental Physics, Physics Institute, University of Bern, Switzerland

${ }^{11}$ Oeschger Centre for Climate Change Research, University of Bern, Switzerland

${ }^{12}$ Priestley International Centre for Climate, University of Leeds, Leeds, UK.

${ }^{13}$ Canadian Centre for Climate Modelling and Analysis, Environment and Climate Change Canada, Victoria, Canada.

${ }^{14}$ Max Planck Institute for Meteorology, Hamburg, Germany

${ }^{15}$ Department of Earth System Science, Woods Institute for the Environment, and Precourt Institute for Energy, Stanford University, US

${ }^{16}$ Met Office Hadley Centre, Exeter, UK

${ }^{17}$ Earth and Environmental Sciences, Lawrence Berkeley National Lab, US

${ }^{18}$ St. Francis Xavier University, Antigonish, Canada

${ }^{19}$ GEOMAR, Helmholtz Centre for Ocean Research, Kiel, Germany

${ }^{20}$ Simon Fraser University, Burnaby, British Columbia, Canada

${ }^{21}$ CNRM, Université de Toulouse, Météo-France, CNRS, Toulouse, France

*corresponding author: damon.matthews@concordia.ca 
The remaining carbon budget represents the total amount of $\mathrm{CO}_{2}$ that can still be emitted in the future while limiting global warming to a given temperature target. The range of carbon budget estimates is wide, however, and can be used to either trivialize the most ambitious mitigation targets as by characterizing them as impossible, or to argue that there is ample time to allow for a gradual transition to a low-carbon economy. Neither of these extremes is consistent with our best understanding of the policy implications of carbon budgets. Understanding the scientific and socio-economic uncertainties affecting the size of the remaining carbon budgets, as well as the methodological choices and assumptions that underlie their calculation, is essential before applying them as a policy tool. Here we discuss uncertainties affecting remaining carbon budget estimates, provide recommendations on how to calculate them in a consistent and transparent way, and discuss their implications for both international and national climate policies.

Here we provide recommendations on how to calculate the remaining carbon budgets in a consistent and transparent way, discuss their implications for both international and national climate policies, as well as related uncertainties.

Remaining carbon budgets are defined as the allowable future $\mathrm{CO}_{2}$ emissions that are consistent with meeting climate targets such as those of the Paris Agreement (see Box 1). Conceptually, the idea of a global emissions budget is a compelling way to frame and communicate the climate mitigation challenge: a finite cap on total $\mathrm{CO}_{2}$ emissions implies clearly that global $\mathrm{CO}_{2}$ emissions must eventually reach net-zero to stabilize global temperatures. Estimates of the remaining carbon budget are subject to large uncertainty, but have also varied considerably among studies owing to the lack of a consistently applied definition, as well as different methodological approaches used to calculate the remaining budgets ${ }^{1,2}$. Furthermore, additional uncertainties are introduced in the process of disaggregating the global budget into national shares for domestic climate policy ${ }^{3-5}$. Given the increasing adoption of carbon budget estimates as a benchmark for national policy discussions, the full range of uncertainties and choices surrounding carbon budget estimates must be articulated and understood.

In this Perspective, we present an overview of the state of our understanding of the remaining carbon budget, with the intent of charting a tractable path through the scientific, policy and ethical considerations required when applying the carbon budget concept to climate policy 
decisions. We characterize the uncertainties and other factors affecting estimates of the remaining carbon budget across four broad categories: (1) geophysical uncertainties associated with physical climate and carbon cycle processes that determine the climate response to emissions; (2) socioeconomic uncertainties that reflect the societal choices and dynamics that determine future emission scenarios; (3) methodological approaches that reflect choices and assumptions made when estimating the global remaining carbon budget; and (4) allocation choices that emerge from the range of ethical and fairness principles that can be used to allocate a portion of the global budget to individual countries, economic sectors and entities such as individual industries and corporations. We discuss each of these in turn, and then offer some concluding thoughts that summarize the robust policy implications of a finite remaining carbon budget.

\section{Box 1: What is a "remaining carbon budget"?}

Here, a remaining carbon budget is the quantity of cumulative or total $\mathrm{CO}_{2}$ emissions that is consistent with limiting global mean warming to a given temperature level. The term "budget" is analogous to a fixed total financial budget, in that spending in excess of annual budget amounts in the near-term requires decreased spending in the future to not exceed the total budget. Here, we distinguish between the total and the remaining carbon budget: (1) the total carbon budget is defined as the total amount of $\mathrm{CO}_{2}$ emissions since the preindustrial reference period that is consistent with a specified peak temperature increase; and (2) the remaining carbon budget, which represents the amount of $\mathrm{CO}_{2}$ that can still be emitted from present-day onwards while staying below the temperature target ${ }^{1,2}$. In both cases, these budgets refer to a total quantity of $\mathrm{CO}_{2}$ emissions (from fossil fuels and land-use change) up to the point in time that $\mathrm{CO}_{2}$ emissions reach net-zero. Importantly, this quantity applies to only $\mathrm{CO}_{2}$ emissions, and does not apply to allowable $\mathrm{CO}_{2}$-equivalent emissions of other gases and aerosols (e.g., methane and nitrous oxide, as calculated using global warming potentials).

There are several variants of carbon budgets that have been used in the literature (e.g. threshold exceedance budget, threshold avoidance budget, threshold return budget and overshoot budget; see Ref. ${ }^{1}$ and Ref. $^{6}$ for a discussion of these variants). We do not use these terms further, and we recommend that they be used only if necessary to explore the sensitivity of carbon budget estimates to different types of emission scenarios or estimation methods.

Another common but distinct use of the term "carbon budget" is to describe the balance of historical sources and sinks of $\mathrm{CO}_{2}$ in the Earth system or for a particular region. In this alternative usage, the term "budget" is similar to annual financial accounting in a closed system without deficits, whereby the sum of the individual positive and negative line items must equal zero. As a prominent example, the Global Carbon Project annually publishes a 
historical global carbon budget, defined as the mean, variations and trends associated with the human perturbation to the global carbon cycle up to present-day ${ }^{7}$. This historical global carbon [cycle] budget combines fossil fuel and land-use $\mathrm{CO}_{2}$ emissions (or sources) with increases in atmospheric, land and ocean carbon reservoirs (also referred to as sinks) and places these sources and sinks in the context of natural carbon cycle processes.

\section{Geophysical basis of carbon budgets}

The proportionality between cumulative $\mathrm{CO}_{2}$ emissions and $\mathrm{CO}_{2}$-induced temperature change is the primary geophysical basis for a finite remaining carbon budget: each additional tonne of $\mathrm{CO}_{2}$ emitted leads to an incremental temperature increase, which implies that $\mathrm{CO}_{2}$ emissions must decrease to net-zero to stabilize global temperature ${ }^{8}$. This proportionality is quantified by the Transient Climate Response to cumulative $\mathrm{CO}_{2}$ Emissions (TCRE), which defines the transient warming per unit cumulative $\mathrm{CO}_{2}$ emissions in a scenario with increasing $\mathrm{CO}_{2}$ emissions (see Box 2). The allowable cumulative $\mathrm{CO}_{2}$ emissions for a given amount of warming are therefore proportional to the inverse of the TCRE ${ }^{1,9}$. However, this relationship only holds for the warming caused by $\mathrm{CO}_{2}$, and not for additional warming (or cooling) caused by other emissions or forcings (e.g., methane, aerosols, or nitrous oxide).

Using the TCRE to estimate the remaining carbon budget for a given temperature target therefore requires an additional estimate of the non- $\mathrm{CO}_{2}$ contribution to future warming ${ }^{1,9-11}$. One approach is to define an "Effective TCRE" to estimate the total anthropogenic warming at a given amount of cumulative $\mathrm{CO}_{2}$ emissions ${ }^{11-13}$ (see Box 2). However, unlike the TCRE, there is no geophysical basis for the Effective TCRE to remain constant in time. In particular, where the TCRE is approximately scenario-independent ${ }^{14,15}$, this does not hold for the Effective TCRE which is affected by the changing rate of emissions of non- $\mathrm{CO}_{2}$ forcers with mostly shorter atmospheric lifetimes ${ }^{16}$. Consequently, while the Effective TCRE can be used to estimate the total carbon budget directly ${ }^{12}$, it is important to use an estimated value of the Effective TCRE at the time that the temperature target is reached in a given scenario (Figure 1). 
(a)
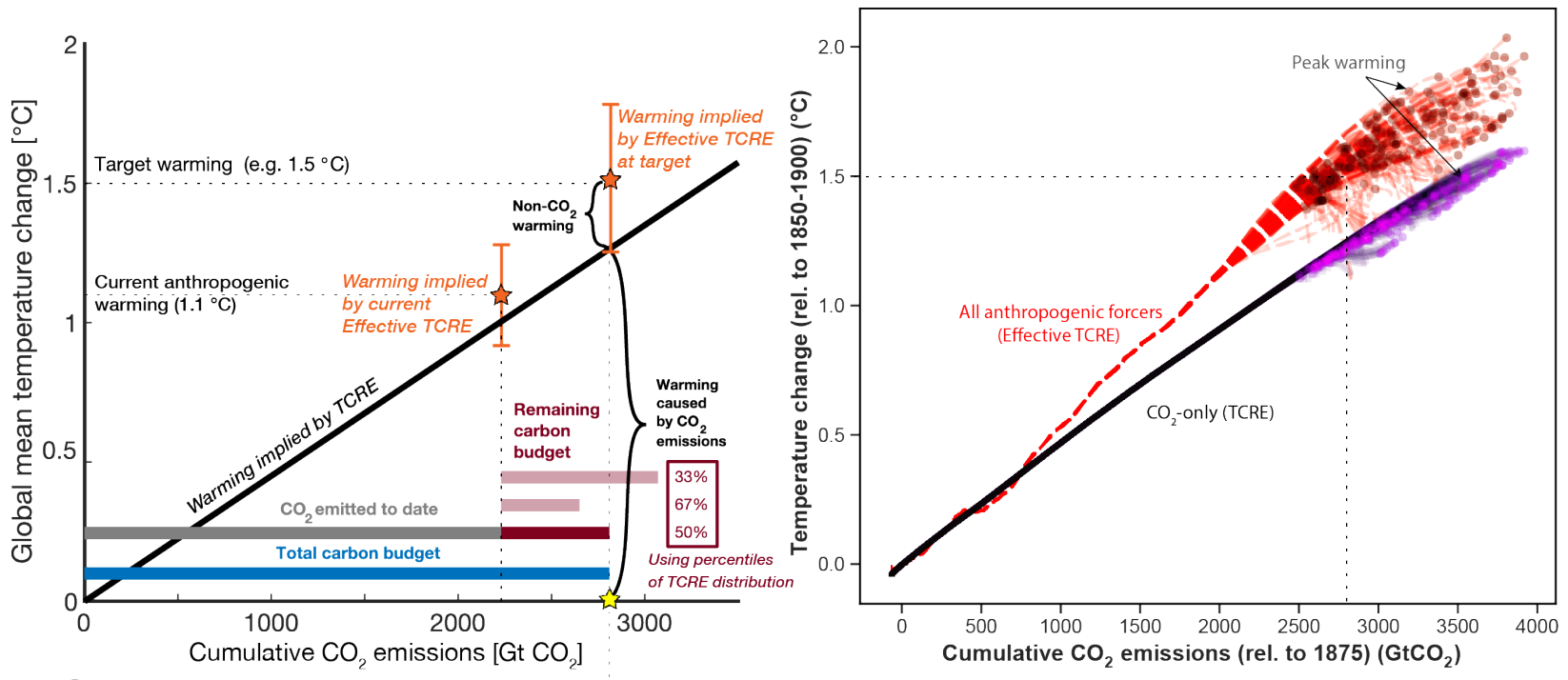

Other contributions to uncertainty

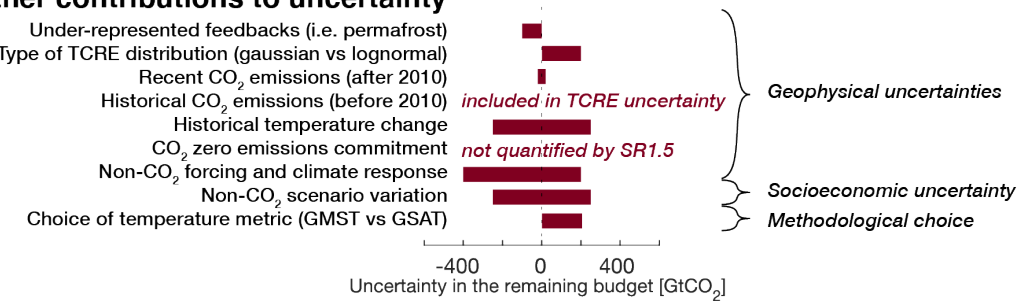

Figure 1: Relationship between the TCRE, the Effective TCRE, and the total and remaining carbon budgets.

(a) Idealized representation of the TCRE, Effective TCRE and related total and remaining carbon budgets. Here, we show the central estimate of the TCRE $\left(0.45^{\circ} \mathrm{C}\right.$ per $\left.1000 \mathrm{Gt} \mathrm{CO}_{2}\right)$ and an Effective TCRE value of $0.53{ }^{\circ} \mathrm{C}$ per 1000 $\mathrm{Gt} \mathrm{CO}_{2}$ at $1.5^{\circ} \mathrm{C}$, which corresponds to the median $\left(50^{\text {th }}\right.$ percentile) remaining carbon budget of $580 \mathrm{Gt} \mathrm{CO}_{2}$ from 2018 onwards reported in the IPCC Special Report on $1.5^{\circ} \mathrm{C}$ (SR1.5; Ref. ${ }^{9}$, Table 2.2 therein). The $67^{\text {th }}$ (420 Gt $\left.\mathrm{CO}_{2}\right)$ and $33^{\text {rd }}\left(840 \mathrm{Gt} \mathrm{CO}_{2}\right)$ percentile budgets are shown in lighter red, reflecting uncertainty in the TCRE only. Other contributions to uncertainty are shown by bars below the plot, showing the amount by which these additional processes affect the median budget estimate (Ref. ${ }^{9}$, Table 2.2 therein). (b) Simulated climate response to CO${ }_{2}$ emissions only (blue) and all anthropogenic drivers (red) for scenarios from the SR1.5 scenario database ${ }^{17,18}$, using the simple model emulator MAGICC7(Refs. $\left.{ }^{19,20}\right)$ with parameter settings corresponding to a TCRE of $0.44^{\circ} \mathrm{C} \mathrm{per} \mathrm{Gt}$ $\mathrm{CO}_{2}$. Temperature change is shown relative to the 1850-1900 period, and cumulative $\mathrm{CO}_{2}$ emissions are calculated from the central year of that period (year 1875). Dots mark the peak warming and the lines end at the point of netzero $\mathrm{CO}_{2}$ emissions in each scenario. The larger spread of red dots relative to purple shows the additional effect of socioeconomic uncertainty on the Effective TCRE as a result of differing non-CO $\mathrm{O}_{2}$ emission scenarios. 


\section{Box 2: The Transient Climate Response to cumulative $\mathrm{CO}_{2}$ Emissions}

A close to proportional relationship between $\mathrm{CO}_{2}$-induced global warming and cumulative $\mathrm{CO}_{2}$ emissions is an emergent property of a range of Earth-system models ${ }^{14,15,21-23}$. The Transient Climate Response to cumulative $\mathrm{CO}_{2}$ Emissions (TCRE) quantifies the temperature change per unit of cumulative $\mathrm{CO}_{2}$ emissions (often expressed as ${ }^{\circ} \mathrm{C}$ per $1000 \mathrm{PgC}$ or per $1000 \mathrm{Gt} \mathrm{CO}_{2}$ emitted). In a climate model, the TCRE defines the temperature change per unit $\mathrm{CO}_{2}$ emissions at the time of doubled $\mathrm{CO}_{2}$, in an idealized experiment where atmospheric $\mathrm{CO}_{2}$ concentration increases at a rate of $1 \%$ per year ${ }^{24,25}$. This TCRE value can then be used to describe the general linear relationship between cumulative $\mathrm{CO}_{2}$ emissions and $\mathrm{CO}_{2}$-induced temperature change (Figure Box 1a, solid line, where the value of the TCRE defines the slope of this line).

The TCRE has been shown to be a good predictor of warming caused by a given quantity of cumulative $\mathrm{CO}_{2}$ emissions across a range of emissions scenarios ${ }^{15}$, though is subject to many uncertain processes that affect both its magnitude (the slope of the line) and its constancy in time (the robustness of the linear response to additional cumulative emissions) (Figure Box 1a). Among Earth system models, the magnitude of the TCRE is strongly related to the transient climate response (TCR) which accounts for at least half of the variation in TCRE values $^{26,27}$; remaining TCRE variation is caused by varying carbon cycle sensitivity to global warming and increasing $\mathrm{CO}_{2}{ }^{27}$ (Figure Box 1b). Model TCRE values are also (though to a lesser extent) related to their Equilibrium Climate Sensitivity (ECS), that is an estimate of the global warming in response to doubling of the atmospheric $\mathrm{CO}_{2}$ concentration once the Earth System reaches an equilibrium. Several models in the recent Sixth Coupled Model Intercomparison Project ${ }^{28}$ (CMIP6) have higher ECS values than the previous generation of models ${ }^{29}$ (CMIP5), most of which are also associated with high TCR and TCRE values. However, some of these high-ECS CMIP6 models have TCR and TCRE values that fall outside of estimates of the observationallyconstrained 5-95\% range $\mathrm{e}^{24,30,31}$ (Figure Box 2 b). Consequently, while these high-ECS models would predict smaller remaining carbon budgets, this should be considered a low-probability outcome given their current lower consistency with observed warming ${ }^{30,32}$. Such results can nevertheless be used to guide quantitative risk assessment of the implications of our imperfect knowledge of climate processes and the associated risks of lowprobability outcomes ${ }^{33}$.

Importantly, the TCRE applies only to warming caused by $\mathrm{CO}_{2}$ emissions, and does not include the additional warming or cooling caused by non- $\mathrm{CO}_{2}$ emissions and other climate drivers. A common approach to incorporate the effect of non- $\mathrm{CO}_{2}$ forcing is to use simulations forced by all anthropogenic drivers, and plot the resulting total anthropogenic warming as a function of cumulative $\mathrm{CO}_{2}$ emissions. This results in a representation of total anthropogenic warming per unit cumulative $\mathrm{CO}_{2}$ emission that includes the effect of all climate drivers ${ }^{34,35}$. Here, we label this the "Effective TCRE" (following Ref. ${ }^{12}$ ), to define the total anthropogenic warming at a given quantity of cumulative $\mathrm{CO}_{2}$ emissions (Figure Box 1a, slope of dashed black line). The Effective TCRE is a measure of warming per unit cumulative $\mathrm{CO}_{2}$ emissions, equal to the TCRE plus an additional amount of scenario-dependent non- $\mathrm{CO}_{2}$ warming. This metric has been used conceptually or explicitly in several previous 
studies to directly infer remaining carbon budgets associated with a given future emission scenario ${ }^{11-13,35-38}$. However, this needs to be done with an understanding that the Effective TCRE is not expected to remain constant in time (see Figure 1) due to its strong dependence on non- $\mathrm{CO}_{2}$ scenario variation and in particular on the potential unmasking of aerosol cooling in scenarios with rapid decreases in aerosol emissions ${ }^{16}$.

(a)

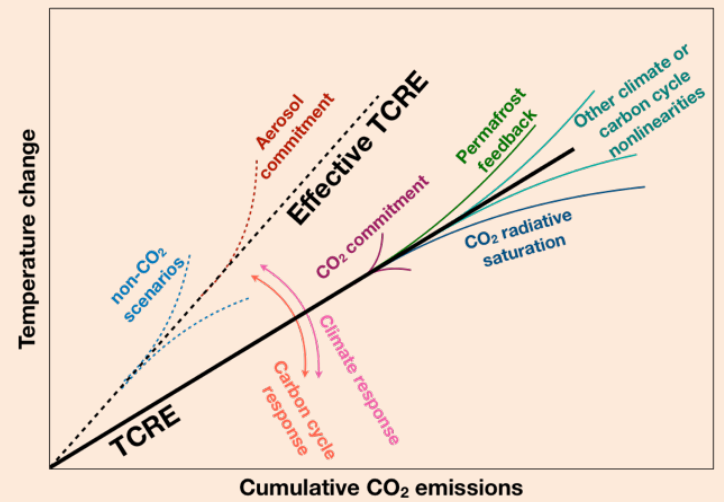

(b)

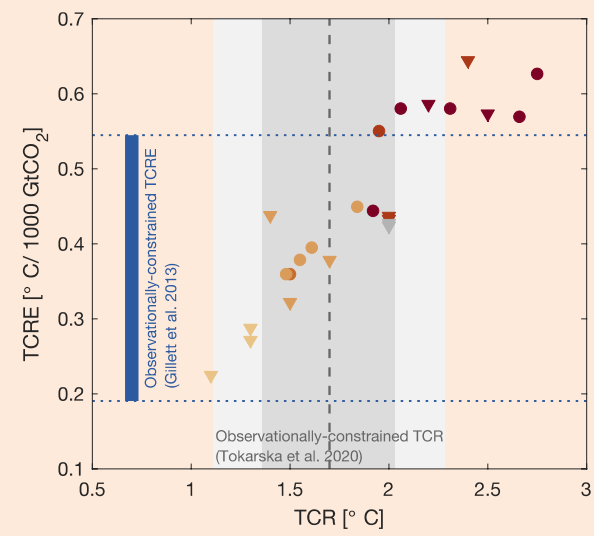

Individual models coloured by ECS values

- $>4.5$

- $3.5-4.5$

- $3.0-3.5$

- $2.5-3.0$

$2-2.5$

unknown

- CMIP6 $\nabla$ CMIP5

Figure Box 2. Uncertain processes affecting the relationship between warming and cumulative $\mathrm{CO}_{2}$ emissions.

(a) Conceptual representation of the Transient Climate Response to cumulative $\mathrm{CO}_{2}$ Emissions (TCRE; the slope of the solid black line), and the Effective TCRE (represented by the dashed black line). Solid coloured arrows indicate scientific uncertainties affecting the value of the TCRE due to the climate (pink) and carbon cycle (orange) response to $\mathrm{CO}_{2}$ emissions ${ }^{24,26}$. Solid coloured lines indicate processes that may lead to deviations from a linear temperature response to cumulative emissions. Notable processes are the additional unrealized warming (or cooling) due past emissions that could occur as $\mathrm{CO}_{2}$ emissions approach zero ${ }^{39,40}$ (CO $\mathrm{CO}_{2}$ commitment; purple), permafrost carbon feedbacks ${ }^{41,42}$ (green), and the increasing saturation of $\mathrm{CO}_{2}$ radiative forcing at high $\mathrm{CO}_{2}$ levels ${ }^{43}$ (dark blue). Other nonlinear climate or carbon cycle processes act in both directions and tend to compensate each other (turquoise) leading to an approximately constant TCRE value across a wide range of cumulative $\mathrm{CO}_{2}$ emissions ${ }^{14,15,24,44}$. Dashed coloured lines indicate additional uncertainties affecting the Effective TCRE as a result of societal choices leading to different non- $\mathrm{CO}_{2}$ greenhouse gas emission scenarios ${ }^{9,10,16,35}$ (dashed blue) and the warming response to decreased aerosol emissions ${ }^{45,46}$ (dashed red). (b) Relationship between model TCRE and TCR values in the CMIP5 models ${ }^{24,47,48}$ (triangles) and CMIP6 model ${ }^{26,30}$ (circles). Grey shading indicates the observationally-constrained TCR median (dashed line), likely range (>66\%; dark grey) and 5-95\% range (light grey), based on the 1981-2017 observed warming trend as a constraint based on Ref. ${ }^{30}$. The blue bar and blue dotted lines indicate observationally-constrained TCRE range (5-95\%) reported by $\operatorname{Ref}^{24}$. 


\section{Geophysical uncertainties affecting the remaining carbon budget}

Geophysical uncertainties affecting the TCRE (see Box 2) will propagate directly to uncertainties in estimates of the remaining carbon budget. In general, there are three types of geophysical uncertainties relevant to the TCRE that affect its robustness as a predictor of the remaining carbon budget. First, differing physical climate and carbon cycle responses to $\mathrm{CO}_{2}$ emissions alter the magnitude of the TCRE. Across Earth system models, TCRE values are generally proportional to models' Transient Climate Response (TCR), though different carbon cycle responses will also produce a range of TCRE values among models with similar TCR values ${ }^{26,27}$ (see Box 2). Better constraints on the TCR value as well as on the carbon cycle response to climate change and increasing $\mathrm{CO}_{2}$ would therefore have the effect of constraining both the TCRE and the remaining carbon budget.

Second, the linearity of the TCRE relationship results from the compensation of individual nonlinear processes that act to both increase and decrease the sensitivity of the temperature response to additional cumulative $\mathrm{CO}_{2}$ emissions ${ }^{43,44,49,50}$. However, there is nevertheless the potential for strong non-linear changes in the strength of particular feedbacks to cause deviations from the TCRE-predicted linearity with increasing emissions. Examples include potential changes to the strength of physical climate feedbacks as a result of changing warming patterns ${ }^{51-53}$ or the behaviour of biogeochemical permafrost and wetland feedbacks that are currently poorly represented in Earth system models ${ }^{42,54}$.

Third, while the TCRE has been shown to be a robust predictor of $\mathrm{CO}_{2}$-induced warming in scenarios with increasing $\mathrm{CO}_{2}$ emissions ${ }^{24,25}$, it is less clear that the TCRE will adequately capture the climate response to scenarios that rapidly decline to net-zero and/or net-negative $\mathrm{CO}_{2}$ emissions ${ }^{41,55}$. In the event that there is unrealized warming or cooling from past $\mathrm{CO}_{2}$ emissions, this lagged temperature change would manifest during the time that $\mathrm{CO}_{2}$ emissions ramp down to zero, causing the temperature response to cumulative emissions to bend upwards or downwards relative to the linear TCRE line. This unrealized commitment from past $\mathrm{CO}_{2}$ emissions has recently been quantified across Earth system models ${ }^{39,40,56}$, and is likely an important contributor to uncertainty in the remaining carbon budget.

Finally, the climate response to non- $\mathrm{CO}_{2}$ forcing changes is an important additional source of geophysical uncertainty affecting carbon budget estimates that is distinct from the contributions 
to TCRE uncertainty discussed above (see "non- $\mathrm{CO}_{2}$ forcing and climate response" bar below Figure 1a; Ref. ${ }^{9}$ ). Given the prominence of aerosol forcing uncertainty in affecting the overall non- $\mathrm{CO}_{2}$ forcing uncertainty, this speaks to the importance of improved estimates of the climate response to present-day aerosol forcing in order to improve our ability to constrain estimates of the remaining carbon budget.

\section{Socioeconomic uncertainties affecting the remaining carbon budget}

Remaining carbon budget estimates are also strongly affected by socioeconomic uncertainties related to our ability to predict the dynamics of socio-political systems and the technological changes that determine the evolution of emissions in future scenarios. Given that the TCRE is relatively robust to variation in $\mathrm{CO}_{2}$ emission scenarios ${ }^{15,43,50}$, the relationship between the TCRE and the remaining carbon budget is only weakly affected by socioeconomic uncertainty. However, the effect of socioeconomic uncertainty is considerably more pronounced for estimates of future non- $\mathrm{CO}_{2}$ warming (see spread of total warming as a function of cumulative emissions across scenarios in Figure 1b, red dots). This relates to the shorter atmospheric lifetimes of many non- $\mathrm{CO}_{2}$ emissions, such that rapid decreases in emissions of short-lived positive climate forcers (such as methane, black carbon and ozone precursors) would effectively limit near-term warming caused by non- $\mathrm{CO}_{2}$ emissions ${ }^{57}$. Conversely, however, rapid decreases in aerosol emissions that produce a negative forcing would amplify non- $\mathrm{CO}_{2}$ warming ${ }^{16}$, a scenario that is likely to occur as a result of decarbonization efforts ${ }^{45,46,58}$.

Although both geophysical and socioeconomic uncertainties can be reduced by further research, socioeconomic uncertainties are also sensitive to human decisions and choices regarding technological development and mitigation actions ${ }^{16}$. This means that policy decisions about where to focus mitigation efforts have the potential to influence the size of the remaining carbon budget by affecting the amount of warming that is caused by $\mathrm{CO}_{2}$ vs. other anthropogenic climate drivers $^{6}$. The balance of effective mitigation of positive short-lived forcers and the potential aerosol warming commitment may be one of the most important determinants of the size of the remaining carbon budget. 


\section{Methodological choices and assumptions affecting remaining carbon budget estimates}

Using a consistent and transparent set of assumptions to calculate the remaining carbon budget is crucial in order to provide clear guidelines for climate policy. Yet, inconsistent choices are often used among different studies that report remaining carbon budget estimates, which unnecessarily inflates the spread of estimates ${ }^{1,2}$. Here, we provide guidelines and recommendations to estimate carbon budgets in a transparent and policy-relevant way, given the many choices and assumptions typically required (Table 1).

First, we recommend estimating carbon budgets for anthropogenic warming only, independent of natural variability (e.g. as estimated by Ref. ${ }^{59}$ ); while this may seem like an obvious statement, it is nevertheless the case that climate policy temperature goals have not been consistently interpreted across different studies ${ }^{60}$. The ultimate objective of the United Nations Framework Convention on Climate Change (UNFCCC) is to prevent "dangerous anthropogenic interference in the climate system" (Article 2). This framing provides a clear rationale for limiting warming caused by all anthropogenic drivers, rather than that caused by the combined effect of anthropogenic warming and natural variability ${ }^{60}$.

Second, we recommend that carbon budgets be defined in relation to a particular policy-relevant climate target. The Paris Agreement ${ }^{61}$ aims to keep global temperatures to "well below $2{ }^{\circ} \mathrm{C}^{\prime \prime}$ and to "pursue efforts to limit warming to $1.5{ }^{\circ} \mathrm{C}$ above pre-industrial temperatures". Consequently, carbon budgets associated with a range of temperature increases between $1.5^{\circ} \mathrm{C}$ and "well below $2{ }^{\circ} \mathrm{C} "$ are those with direct relevance for the Paris Agreement goal. Budgets for $2^{\circ} \mathrm{C}$ or higher can be used to gauge the amount of effort needed to stay below higher warming levels, but are outside the current policy framing of the Paris Agreement.

Third, choices about the desired level of risk avoidance must be defined when estimating carbon budgets. Carbon budgets have typically been reported as corresponding to a $50 \%$ or $67 \%$ percent probability of staying below a given temperature target when the carbon budget is fully emitted, given known and quantified uncertainties ${ }^{35}$.

Fourth, the proxy for the pre-industrial reference period that has been used in recent IPCC reports $^{9,62}$ is the 1850-1900 average, which we recommend adopting for consistency with these analyses. We recognize that temperatures during this period may have already increased relative to the previous century ${ }^{59,63,64}$, though adopting an earlier baseline period is currently difficult 
owing to limited observational data on both temperature and cumulative $\mathrm{CO}_{2}$ emissions prior to 1850.

Fifth, it is important to be explicit about the choice of temperature change metric. The relative merits of using a blended air-water temperature that is masked according to observational coverage (Global Mean Surface Temperature, GMST), a full-coverage global surface air temperature (GSAT), or a combination of the two, to represent observed historical warming have been discussed extensively elsewhere ${ }^{1,2,65}$; we do not offer a specific recommendation here other than that the choice of metric be clear and justified, both for historical warming and TCRE.

Sixth, we recommend adopting our carbon budget definition of total emissions up to the point in time that $\mathrm{CO}_{2}$ emissions reach net-zero (see Box 1), which is likely to correspond closely to the timing of peak temperature change ${ }^{9}$. This choice also avoids the need for assumptions regarding the potential feasibility of net negative $\mathrm{CO}_{2}$ emissions to reverse temperature overshoots. For model simulations, this requires using emissions scenarios that contain internally-consistent $\mathrm{CO}_{2}$ and non- $\mathrm{CO}_{2}$ emissions, which are also broadly consistent with a desired peak temperature target, rather than scenarios where temperatures exceed the target indefinitely or exceed (overshoot) and return to the target in question.

For the other methodological choices listed in Table 1, our key recommendation is for each choice to be documented to clarify the assumptions embedded in analyses, and to discuss (quantitatively if possible) how choices may affect the results. Lack of clarity with respect to these assumptions and choices can result in widely varying carbon budget estimates that risk being applied inappropriately to policy questions. For example, carbon budget estimates that are based on the assumption that non- $\mathrm{CO}_{2}$ forcing will follow a high-emission scenario should not be applied uncritically to the case of ambitious mitigation scenarios with decreasing non- $\mathrm{CO}_{2}$ emissions. Similarly, budget estimates using the GMST temperature metric are not well suited to estimate the requirements for avoiding climate impacts that have been calculated using GSAT change. Consistent and clear methodological choices are therefore critical to minimize the risk of misuse of carbon budget estimates in policy applications. 


\section{Table 1: Choices and assumptions that are typically required when estimating total or remaining carbon budgets for global temperature targets. Where appropriate, recommended choices are marked with an asterisk (*).}

\begin{tabular}{|c|c|c|}
\hline Choice & Options & Issues to consider \\
\hline \multirow[t]{2}{*}{$\begin{array}{l}\text { Definition of global } \\
\text { warming }\end{array}$} & (*) Anthropogenic warming only & $\begin{array}{l}\text { Relevant to international climate targets aimed at limiting global } \\
\text { temperature increase }{ }^{60} \text {; requires a method to isolate the anthropogenic } \\
\text { contribution to observed or model-simulated temperature change }{ }^{24,59} \text {. }\end{array}$ \\
\hline & $\begin{array}{l}\text { Anthropogenic warming + natural climate } \\
\text { variability }\end{array}$ & $\begin{array}{l}\text { Directly observable and simulated by global climate models; however, } \\
\text { natural climate variability, whether externally forced (by volcanoes or } \\
\text { solar activity) or unforced (i.e. internal variability of the climate system), } \\
\text { causes inter-annual to decadal-scale warming or cooling trends that are not } \\
\text { relevant to international climate goals }{ }^{60,66,67} \text {. }\end{array}$ \\
\hline \multirow[t]{3}{*}{ Target temperature } & $(*) 1.5^{\circ} \mathrm{C}$ & Most ambitious target level in the Paris Agreement. \\
\hline & (*) "well below $2{ }^{\circ} \mathrm{C}$ " & Primary Paris Agreement target, but not precisely defined. \\
\hline & $2{ }^{\circ} \mathrm{C}$ or higher & Warming levels that exceed the Paris Agreement target range. \\
\hline $\begin{array}{l}\text { Probability of not } \\
\text { exceeding the target }\end{array}$ & $50 \%, 67 \%, 90 \% \ldots$ & $\begin{array}{l}\text { Remaining carbon budgets are typically estimated to be in line with a } \\
50 \%, 67 \% \text { or sometimes } 90 \% \text { probability of successfully limiting warming } \\
\text { to the temperature threshold of interest. The choice of which budget to } \\
\text { adopt as a global target depends on societal risk avoidance preferences. }\end{array}$ \\
\hline \multirow[t]{3}{*}{$\begin{array}{l}\text { Pre-industrial } \\
\text { reference period }\end{array}$} & (*) $1850-1900$ average & $\begin{array}{l}\text { Current proxy for pre-industrial climate }{ }^{62} \text {, corresponding with the } \\
\text { beginning of available instrumental temperature records. }\end{array}$ \\
\hline & $1860-1880$ average & $\begin{array}{l}\text { Period representing the first } 20 \text { years available in the HadCRUT } \\
\text { temperature dataset }{ }^{68} \text {, at times used because no major volcanic eruption } \\
\text { took place during these years. }\end{array}$ \\
\hline & $1720-1800$ average & $\begin{array}{l}\text { Suggested by Ref. }{ }^{63} \text { as a better estimate of climate conditions prior to } \\
\text { human influence, but direct observations of global temperature are not } \\
\text { available, and emissions uncertainty prior to } 1850 \text { is very large, posing } \\
\text { difficulty for consistent estimates of historical cumulative emissions from } \\
\text { earlier time periods. }\end{array}$ \\
\hline \multirow[t]{2}{*}{$\begin{array}{l}\text { Temperature change } \\
\text { metric }\end{array}$} & $\begin{array}{l}\text { Observed (blended air-water and/or } \\
\text { masked) temperature (global mean } \\
\text { surface temperature, or GMST) }\end{array}$ & $\begin{array}{l}\text { Directly observable; calculated as a combination of surface air } \\
\text { temperatures over land and sea ice, with surface water temperature over } \\
\text { ocean; incomplete spatial coverage }{ }^{69} \text { unless infilling technique used to } \\
\text { extrapolate to areas with no observations }{ }^{70} \text {; spatial definition changes over } \\
\text { time as sea ice cover changes }{ }^{2} \text {. }\end{array}$ \\
\hline & Global surface air temperature (GSAT). & $\begin{array}{l}\text { Average of surface air temperature with complete global coverage; typical } \\
\text { output of global models, but not currently available from observational } \\
\text { estimates of global temperature change; historical GSAT warming has } \\
\text { been estimated to be about } 0.1^{\circ} \mathrm{C} \text { higher than that based on GMST } \\
\text { though recent improvements to spatial infilling techniques in GMST } \\
\text { products have decreased this difference. }\end{array}$ \\
\hline \multirow[t]{3}{*}{$\begin{array}{l}\text { Nature of } \\
\text { temperature change }\end{array}$} & (*) Peak temperature & $\begin{array}{l}\text { The timing of peak temperature should match closely the timing of net- } \\
\text { zero } \mathrm{CO}_{2} \text { emissions }{ }^{9} \text { which avoids the need for assumptions related to the } \\
\text { reversibility of temperature overshoots. }\end{array}$ \\
\hline & $\begin{array}{l}\text { Temperature at some level of cumulative } \\
\text { emissions }\end{array}$ & $\begin{array}{l}\text { No strict limit on maximum temperature change: temperature may exceed } \\
\text { the target after the point at which cumulative emissions are calculated. }\end{array}$ \\
\hline & Temperature at some year (e.g. 2100) & $\begin{array}{l}\text { No strict limit on maximum temperature change: temperature may exceed } \\
\text { target either before (overshoot and return scenarios) or after selected year. }\end{array}$ \\
\hline $\begin{array}{l}\text { Non- } \mathrm{CO}_{2} \text { scenario } \\
\text { choice }\end{array}$ & $\begin{array}{l}(*) \text { Non- } \mathrm{CO}_{2} \text { scenario consistent with } \\
\mathrm{CO}_{2} \text { emissions that decline to net-zero }\end{array}$ & $\begin{array}{l}\text { Requires an internally-consistent } \mathrm{CO}_{2} \text { and non- } \mathrm{CO}_{2} \text { emission scenario that } \\
\text { is also consistent with the desired target, and } / \text { or an embedded economic } \\
\text { model that generates consistent } \mathrm{CO}_{2} \text { and non- } \mathrm{CO}_{2} \text { emissions } \mathrm{e}^{9,73} \text {. }\end{array}$ \\
\hline
\end{tabular}




\begin{tabular}{|c|c|c|}
\hline & $\begin{array}{l}\text { Non- } \mathrm{CO}_{2} \text { forcing consistent with high- } \\
\text { emissions (or other arbitrary) emission } \\
\text { scenario }\end{array}$ & $\begin{array}{l}\text { Non- } \mathrm{CO}_{2} \text { forcing is not consistent with mitigation efforts to limit warming } \\
\text { to the target, potentially leading to either an under- or overestimate of the } \\
\text { remaining carbon budget }{ }^{10,11,41} \text {. }\end{array}$ \\
\hline \multirow[t]{2}{*}{$\begin{array}{l}\text { Treatment of aerosol } \\
\text { forcing uncertainty }\end{array}$} & $\begin{array}{l}\text { Single model run for time-series of } \\
\text { historical and future aerosol forcing }\end{array}$ & $\begin{array}{l}\text { Results are contingent on the model and/or forcing scenario used and do } \\
\text { not include uncertainty associated with aerosol forcing or the climate } \\
\text { response to decreased future aerosol emissions }{ }^{10} \text {. }\end{array}$ \\
\hline & Assumed range of forcing & $\begin{array}{l}\text { Requires many model simulations or other methods to sample } \\
\text { uncertainty }{ }^{9,22} \text {. }\end{array}$ \\
\hline \multirow[t]{2}{*}{$\begin{array}{l}\text { Treatment of land- } \\
\text { use } \mathrm{CO}_{2} \text { emissions }\end{array}$} & $\begin{array}{l}\text { Prescribed or treated as interchangeable } \\
\text { with fossil fuel emissions }\end{array}$ & $\begin{array}{l}\text { Cumulative emissions from land-use are known, but biophysical and } \\
\text { indirect carbon cycle effects of land-use change are not accounted for. }\end{array}$ \\
\hline & $\begin{array}{l}\text { Simulated by model from prescribed } \\
\text { land-use change scenario }\end{array}$ & $\begin{array}{l}\text { Biophysical and other effects of land-use change accounted for, but } \\
\text { cumulative emissions from land-use are complex to diagnose, often } \\
\text { requiring additional simulations } s^{7-76} \text {. In the absence of diagnosed land-use } \\
\text { emission information, some studies have assumed the same land-use } \\
\text { change emissions in all model simulations }{ }^{36-38} \text {. }\end{array}$ \\
\hline \multirow{3}{*}{$\begin{array}{l}\text { Treatment of } \mathrm{CO}_{2} \\
\text { zero emission } \\
\text { commitment (ZEC) }\end{array}$} & Assumed to be zero or negligible & $\begin{array}{l}\text { This is the approach taken by Ref. }{ }^{9} \text {, but results in unquantified } \\
\text { uncertainty associated with the ZEC. }\end{array}$ \\
\hline & $\begin{array}{l}\text { Assumed to have a positive or negative } \\
\text { value }\end{array}$ & $\begin{array}{l}\text { When combined with a method that uses TCRE directly, a positive ZEC } \\
\text { would reduce the remaining carbon budget to account for unrealized } \\
\text { warming after } \mathrm{CO}_{2} \text { emissions are halted }{ }^{1,56} \text {. Similarly, a negative } \mathrm{ZEC} \\
\text { would increase the remaining budget, but only if its timescale is shorter } \\
\text { than the pace of emission reductions to net-zero } \mathrm{CO}_{2} \text {. }\end{array}$ \\
\hline & $\begin{array}{l}\text { Simulated by model using scenarios } \\
\text { where } \mathrm{CO}_{2} \text { emissions decrease to net-zero }\end{array}$ & $\begin{array}{l}\text { The effect of the } \mathrm{CO}_{2} \mathrm{ZEC} \text { is accounted for in simulations of ambitious } \\
\text { mitigation scenarios, as any unrealized warming or cooling from past } \\
\text { emissions would typically be realized during the time that emissions fall } \\
\text { to zero. }\end{array}$ \\
\hline \multirow[t]{3}{*}{$\begin{array}{l}\text { Treatment of } \\
\text { overshoot scenarios / } \\
\text { reversibility }\end{array}$} & $\begin{array}{l}\text { Climate response to carbon dioxide } \\
\text { removal assumed to be the same as } \\
\text { response to emissions }\end{array}$ & $\begin{array}{l}\text { Many recent studies are based on this assumption (see Ref. } 1 \text { for a } \\
\text { summary of different studies). This assumption is not supported if the } \mathrm{CO}_{2} \\
\text { warming commitment (ZEC) is non-zero }\end{array}$ \\
\hline & Overshoot scenario simulated explicitly & Resulting budget is specific to overshoot scenarios ${ }^{41,55}$. \\
\hline & Overshoot scenarios excluded & Resulting budget may not apply to overshoot scenarios ${ }^{42}$. \\
\hline \multirow[t]{2}{*}{$\begin{array}{l}\text { Treatment of } \\
\text { permafrost feedback }\end{array}$} & $\begin{array}{l}\text { Included in model simulation, or using } \\
\text { TCRE from models that include this } \\
\text { feedback }\end{array}$ & $\begin{array}{l}\text { Resulting budget does not need to be adjusted for this feedback }{ }^{41} \text {, but } \\
\text { timescale is important as permafrost feedbacks have a long time } \\
\text { constant }^{78,79} \text {. }\end{array}$ \\
\hline & $\begin{array}{l}\text { Not included in model or using TCRE } \\
\text { range from CMIP5 models }\end{array}$ & $\begin{array}{l}\text { Budget should be adjusted to account for the effect of this feedback, and } \\
\text { timescale needs to be stated given the feedback's time dependency9. }\end{array}$ \\
\hline $\begin{array}{l}\text { Treatment of other } \\
\text { under- or } \\
\text { unrepresented } \\
\text { feedbacks }\end{array}$ & $\begin{array}{l}\text { Clarity about which feedbacks are } \\
\text { included and which are not }\end{array}$ & $\begin{array}{l}\text { Representation and strength of feedbacks vary among models, which is } \\
\text { part of the explanation for the existing TCRE range. In general, any new } \\
\text { positive (amplifying) feedback would increase the TCRE (and decrease } \\
\text { the budget), and a new negative (attenuating) feedback would decrease the } \\
\text { TCRE (and increase the budget) }{ }^{1} \text {. }\end{array}$ \\
\hline
\end{tabular}




\section{Application of remaining carbon budgets to international and national climate policy}

Carbon budgets are a powerful guide for international policy, providing a way to gauge the consistency of national emission targets with global temperature goals. To do so, the total quantity of remaining $\mathrm{CO}_{2}$ emissions must first be distributed over time so as to align with the target years of national emission pledges. Figure 2 illustrates one such time distribution, in which a scenario of linearly decreasing $\mathrm{CO}_{2}$ emissions to zero at 2040 (for a $1.5^{\circ} \mathrm{C}$ carbon budget) or 2060 (for "well below $2{ }^{\circ} \mathrm{C}$ " budget) is discretized into 5-year budgets that are compatible with the remaining carbon budget. Such subdivided budgets could be tracked and used to inform the 5-year global stocktake process as part of the implementation of the Paris Agreement, whose mandate is to assess the consistency of emissions targets with the long-term temperature goal. Currently, emissions from national pledges are expected to exceed the nearterm budget allowances shown in Figure $2^{80,81}$. This raises important questions of intergenerational equity as we are either accruing an emissions debt to future generations by borrowing allowable emissions from the future allowance, tasking future generations with the challenge of removing anthropogenic $\mathrm{CO}_{2}$ from the atmosphere, or we are committing these future generations to climate change in excess of our stated climate target.

To be useful as a benchmark for national climate policy, the global remaining carbon budget must be further subdivided among nations. There are many choices involved in the distribution of the remaining global carbon budget to individual nations; such decisions often reflect different ways of accounting for unequal national circumstances ${ }^{3,4,82-85}$ (see Box 3). Given the contentious and highly context-specific nature of such distributions, the UNFCCC has chosen not to develop rules or instruct nations as to how to set their own emissions targets. National carbon budgets are therefore currently unilateral choices that can help nations to organize their mitigation efforts, but may not bear any real resemblance to or consistency with the overall global budget. Currently, many nations have designed their NDCs using the most generous of available allocation principles for their country ${ }^{83}$. This suggests a need for international mechanisms to promote the evaluation and iterative reassessment of national budget allowances to ensure consistency with the global budget (Box 3).

Despite the challenges associated with fairly allocating the global budget to nations, the idea of a finite national carbon budget nevertheless has enormous conceptual importance for national 
policy decisions. For example, short-term carbon budgets could be adopted and reported on in a manner similar to fiscal budgets ${ }^{86}$; the simple act of doing so has the potential to embed national climate targets in a much more tangible way across government decision-making processes. The recent adoption of national carbon budgets in the United Kingdom and the EU, including commitments to net-zero emissions by 2050 , are good examples of such an approach. The adoption of finite national budgets would also lend new weight to discussions surrounding new infrastructure construction, and particularly new fossil fuel energy infrastructure. Two recent analyses suggest that global "committed emissions" associated with existing infrastructure (i.e. the future emissions that are expected to occur over the typical operating lifetime of existing infrastructure) are close to or exceed the remaining carbon budgets for our most ambitious climate targets $^{87,88}$. The committed emissions associated with new infrastructure projects could therefore be weighed against a country's remaining carbon budget to determine whether the infrastructure in question is consistent with our climate targets. Furthermore, should a given nation's emissions exceed their share of the global budget, the resulting emission debts ${ }^{4,89}$ could be used as a metric to inform decision-making related to international climate finance. 


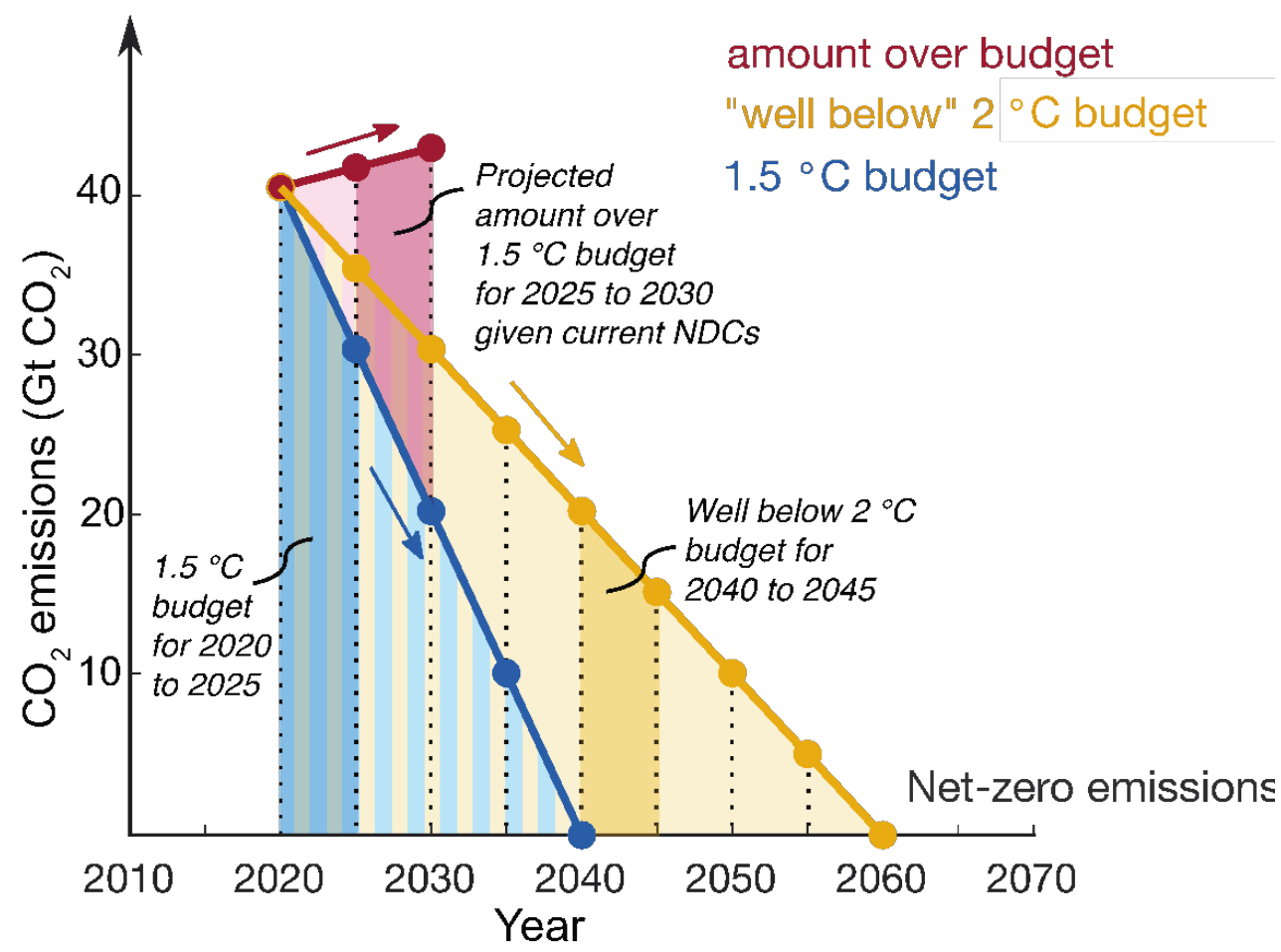

Figure 2. Illustrative example of distributing the remaining carbon budget over time into 5-year discrete time intervals. The years of net-zero $\mathrm{CO}_{2}$ emissions shown here are approximately consistent with the estimates of the $67^{\text {th }}$ percentile remaining budgets from SR1. $5^{9}$ for $1.5^{\circ} \mathrm{C}(420 \mathrm{GtCO}$ after 2017; area under the blue line) and for an illustrative "well below $2{ }^{\circ} \mathrm{C}$ " interpretation, here taken to be $1.75{ }^{\circ} \mathrm{C}\left(800 \mathrm{Gt} \mathrm{CO}_{2}\right.$ after 2017; area under the yellow line). The red shaded regions indicate projected amounts over budget, reflecting estimates of global $\mathrm{CO}_{2}$ emissions between now and 2030 following current national emission pledges (Nationally-Determined Contributions, or $N D C s)^{81}$. We note that the linearly decreasing trajectories illustrated here are clearly an idealized scenario and do not incorporate aspects of cost-effectiveness; however, the small size of remaining carbon budgets for the Paris Agreement goal clearly requires stronger reductions in global $\mathrm{CO}_{2}$ emissions in the next decades than are captured by current $N D C S^{81}$. 


\section{Box 3: Issues of fairness and equity when allocating the remaining carbon budget to countries}

Estimates of the remaining carbon budget provide a global envelope within which future societies have to operate if we intend to limit global warming to a specific level. However, translating this global budget to national

allocations that define what would be an appropriate or fair share of this budget for a single country is an exercise fraught with value judgments which have little relation to the geophysical underpinnings of carbon budgets. Here, science can at best inform and quantify the implications of what are largely subjective choices by individual countries or systems to distribute quotas among countries.

Over time, many so-called fairness or equity principles have been suggested and explored to try to understand what would be a fair allocation of the remaining carbon budget. These principles are largely based on concepts of responsibility, equality and capability across nations ${ }^{90}$ (Figure Box 3). Responsibility addresses the fact that countries have contributed differently to the warming we are currently experiencing, and have also had access to varying levels of understanding over time about the impact of greenhouse gas emissions on the climate. Equality reflects the idea of the human right to development, and that each individual is entitled to equal access to the means of development. This principle can be used to imply an equal entitlement to the production of greenhouse gas emissions, though it is also the case that development can be achieved via low-emission technologies and activities. Capability reflects the fact that different countries can be in quite different positions regarding their capacity to address the challenge of climate change mitigation, be it in terms of financial resources, technical expertise or institutional context. Historically, this capability has been closely related to a country's degree of industrialization, and its associated greenhouse gas emissions. These various principles are well established in the United Nationals Framework Convention on Climate Change which states that countries should participate in responding to climate change "in accordance with their common but differentiated responsibilities and respective capabilities and their social and economic conditions".

A wide variety of ways exist to translate these equity principles by means of quantitative proxies into a distribution method to allocate the global remaining carbon budget to particular countries ${ }^{83}$. The resulting allocations can be positive or negative; that is, they can represent either an emissions allowance or an emissions debt. Allocation methods also vary considerably in their degree of fairness, and some are generally considered to be explicitly unfair. For example, an equal-shares - or grandfathering - allocation approach is often used to claim future emissions rights based on the current distribution of emissions among countries. This allocation method does not account for differing historical responsibility or the history of colonial relationships among countries, and instead rewards historical polluters for their current high share of global emissions.

Translating the global remaining carbon budget to country allocations is thus not a scientific-driven choice but one that represents an interplay and continuous discussion between ethics, justice, society and geophysics ${ }^{91,92}$

(Figure Box 3). Currently, when either implicitly or explicitly selecting a fairness principle, countries almost 
exclusively choose an approach that provides them with a disproportionately large share of the remaining carbon budget when seen from the perspective of another country ${ }^{93}$. This suggests an ongoing need for international cooperation and oversight to achieve consistency between national emissions budgets and international climate targets.

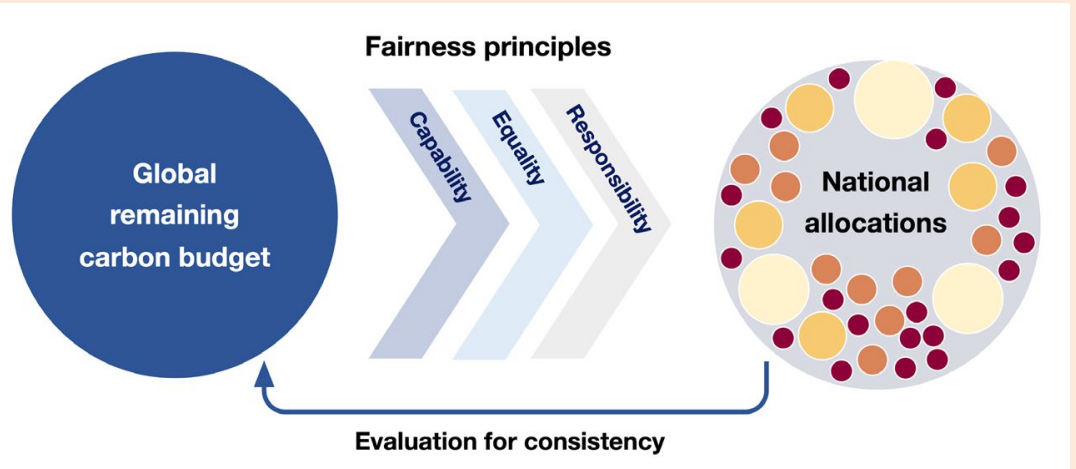

Figure Box 3. Allocating the global remaining carbon budget to individual nations. Any such allocation requires subjective choices and application of fairness principles related to a country's responsibility for climate changes, its capability to achieve mitigation goals, and the importance of equality among countries. Coherence between the sum of national allocations and the global allowable budget is unlikely to emerge from this allocation process, though could be achieved with additional evaluation and iterative reassessment of national allocations. 


\section{Policy implications of a finite remaining carbon budget}

The most important policy implication of a finite carbon budget is the need to achieve net-zero $\mathrm{CO}_{2}$ emissions in order to stabilize global temperature. This framing has been used to inform ongoing and ambitious mitigation efforts in 71 countries and over 100 cities, as well as over 500 businesses that have set net-zero emission targets for a specified year ${ }^{81}$. The concept of a carbon budget has therefore been an effective communication tool in mobilizing individual countries or regions to set net-zero emission reduction targets. However, it is important to reiterate that in order to be consistent with Paris temperature goals, a net-zero $\mathrm{CO}_{2}$ emission target must also be accompanied by aggressive mitigation of non- $\mathrm{CO}_{2}$ emissions such as methane, nitrous oxide and black carbon. Both net-zero $\mathrm{CO}_{2}$ emissions and decreasing non- $\mathrm{CO}_{2}$ forcing are likely required to achieve stable global temperatures ${ }^{73}$.

Another important policy implication is that the size of the remaining carbon budget is sensitive to societal choices for mitigating non- $\mathrm{CO}_{2}$ emissions, as well as the effect of $\mathrm{CO}_{2}$ mitigation efforts on co-emitted non- $\mathrm{CO}_{2}$ species ${ }^{10,11,94}$. However, while the remaining carbon budget is sensitive to non- $\mathrm{CO}_{2}$ emission scenarios, it does not dictate a particular $\mathrm{CO}_{2}$ mitigation pathway over time. This, in turn, highlights the important question of whether $\mathrm{CO}_{2}$ emissions exceeding the budget can be reversed via carbon dioxide removal (CDR) technologies. While the climate response to positive and negative $\mathrm{CO}_{2}$ emissions has been shown to be approximately symmetrical $^{55,77}$, CDR technologies are expensive and challenging to deploy at scale ${ }^{95,96}$, and will also need to remove $\mathrm{CO}_{2}$ that oceans and lands will release again in response to declining atmospheric $\mathrm{CO}_{2}{ }^{97-99}$. Furthermore, the technologies used to produce and remove $\mathrm{CO}_{2}$ emissions will likely not produce (or remove) the same types or quantities of co-emitted non- $\mathrm{CO}_{2}$ emissions. Current scientific understanding therefore suggests that it will neither be easy nor necessarily possible to achieve the level of CDR required to swiftly reverse the effect of substantial emissions in excess of the available budget ${ }^{99,100}$, particularly with respect to longtimescale responses such as sea level ${ }^{99}$ or other changes in the marine environment ${ }^{101,102}$.

Finally, there remain substantial challenges associated with how to equitably share the remaining carbon budget among nations ${ }^{83,93}$. Issues of fairness are have been interpreted differently across nations, with the result that the sum of all current national targets would produce emissions that exceed the global budget for limiting warming to $1.5^{\circ} \mathrm{C}$ or "well below $2{ }^{\circ} \mathrm{C}$ " 83,93 . This in turn 
suggests means that many of the countries who have presented their current targets as "fair and ambitious" $"$ have in fact adopted targets that are neither. To achieve a coherent set of national allocations that reflect principles of fairness and are also consistent with the global budget, it will be essential to empower and strengthen international cooperation to achieve an iterative process of evaluating and strengthening national carbon budgets.

Carbon budgets are a powerful conceptual tool with clear potential to inform climate policy. Estimates of the remaining carbon budget can be used as a benchmark for international targets, and as a rationale for setting and monitoring progress towards net-zero national $\mathrm{CO}_{2}$ emissions targets. The latest estimates of the remaining carbon budget suggest that while the global budget is small and rapidly decreasing, there is nevertheless a reasonable chance that the Paris Agreement goals remain within reach. However, this window of opportunity is closing with each passing year of tentative and insufficient action. Halting climate change at acceptable levels will require large and rapid increases in effort on the part of both international and national players in the climate mitigation challenge. 


\section{Acknowledgements}

We are grateful for the opportunity to have discussed these and other issues at the International Workshop on the Remaining Carbon Budget, organized with the support of the Global Carbon Project, the CRESCENDO project, Stanford University, the University of Melbourne, and Simon Fraser University. HDM has been supported by funding from the Concordia University Research Chair program and the Natural Sciences and Engineering Research Council of Canada (NSERC Discovery Grant: RGPIN-201704159). KBT, JR, PMF, and RS were supported by the European Union's Horizon 2020 research and innovation programme under grant agreement No 820829 (CONSTRAIN project). JGC was supported by the Australian National Environmental Science Program - Earth Systems and Climate Change Hub. PF and TLF were supported by the European Union's Horizon 2020 research and innovation programme under grant agreement No 821003 (4C project). TLF was also supported by the Swiss National Science Foundation under grant PP00P2_170687. AHMD and KZ are supported by the Natural Sciences and Engineering Research Council of Canada Discovery Grant Program. CDJ was supported by the Joint UK BEIS/Defra Met Office Hadley Centre Climate Programme (GA01101) and by H2020 EU project CRESCENDO under grant agreement No 641816. RBJ and JGC acknowledge support from the Gordon and Betty Moore Foundation (GBMF5439).

\section{Author contributions}

HDM initiated the study and wrote the manuscript with inputs from KBT, ZN, JR, MM, NM, JGC, TLF, and suggestions from other authors. HDM, KBT and ZN made the figures. All authors participated in discussions at the International Workshop on the Remaining Carbon budget which initiated this work, as well as in manuscript editing and revisions.

\section{Competing Interests}

The authors declare no competing interests.

\section{Data availability}

SR1.5 scenarios have been made available through refs 17,18 at: https://data.ene.iiasa.ac.at/iamc-

\section{5c-explorer/}

\section{Code availability}

The MAGICC7 model emulator is available from ZRJN upon request.

Codes for producing the figures are available from HDM or KBT upon request. 


\section{References}

1. Rogelj, J., Forster, P. M., Kriegler, E., Smith, C. J. \& Séférian, R. Estimating and tracking the remaining carbon budget for stringent climate targets. Nature 571, 335-342 (2019).

2. Tokarska, K. B. et al. Recommended temperature metrics for carbon budget estimates, model evaluation and climate policy. Nat. Geosci. 12, 964-971 (2019).

3. Raupach, M. R. et al. Sharing a quota on cumulative carbon emissions. Nature Climate Change 4, 873 (2014).

4. Gignac, R. \& Matthews, H. D. Allocating a $2{ }^{\circ} \mathrm{C}$ cumulative carbon budget to countries. Environ. Res. Lett. 10, 075004 (2015).

5. CONSTRAIN, 2019: ZERO IN ON the remaining carbon budget and decadal warming rates. The CONSTRAIN Project Annual Report 2019, DOI: https://doi.org/10.5518/100/20.

6. Rogelj, J. et al. Differences between carbon budget estimates unravelled. Nature Climate Change 6, 245-252 (2016).

7. Friedlingstein, P. et al. Global Carbon Budget 2019. Earth System Science Data 11, 17831838 (2019).

8. Matthews, H. D. \& Caldeira, K. Stabilizing climate requires near-zero emissions. Geophysical Research Letters 35, (2008).

9. Rogelj, J. et al. Mitigation pathways compatible with $1.5^{\circ} \mathrm{C}$ in the context of sustainable development. In: Global warming of $1.5^{\circ} \mathrm{C}$. An IPCC special report on the impacts of global warming of $1.5^{\circ} \mathrm{C}$ above pre-industrial levels and related global greenhouse gas emission pathways, in the context of strengthening the global response to the threat of climate change, sustainable development, and efforts to eradicate poverty [V. Masson-Delmotte, P. Zhai, H. O. Pörtner, D. Roberts, J. Skea, P.R. Shukla, A. Pirani, W. Moufouma-Okia, C. Péan, R. Pidcock, S. Connors, J. B. R. Matthews, Y. Chen, X. Zhou, M. I. Gomis, E. Lonnoy, T. Maycock, M. Tignor, T. Waterfield (eds.)]. In Press. (2018).

10. Mengis, N., Partanen, A.-I., Jalbert, J. \& Matthews, H. D. $1.5^{\circ} \mathrm{C}$ carbon budget dependent on carbon cycle uncertainty and future non- $\mathrm{CO}_{2}$ forcing. Sci Rep 8, 5831 (2018).

11. Tokarska, K. B., Gillett, N. P., Arora, V. K., Lee, W. G. \& Zickfeld, K. The influence of non- $\mathrm{CO}_{2}$ forcings on cumulative carbon emissions budgets. Environ. Res. Lett. 13, 034039 (2018).

12. Matthews, H. D. et al. Estimating Carbon Budgets for Ambitious Climate Targets. Curr Clim Change Rep 3, 69-77 (2017).

13. Millar, R. J. \& Friedlingstein, P. The utility of the historical record for assessing the transient climate response to cumulative emissions. Phil. Trans. R. Soc. A 376, 20160449 (2018).

14. Matthews, H. D., Gillett, N. P., Stott, P. A. \& Zickfeld, K. The proportionality of global warming to cumulative carbon emissions. Nature 459, 829-832 (2009).

15. Zickfeld, K., Arora, V. K. \& Gillett, N. P. Is the climate response to $\mathrm{CO}_{2}$ emissions path dependent? Geophysical Research Letters 39, (2012).

16. Mengis, N. \& Matthews, D. Non- $\mathrm{CO}_{2}$ forcing changes will likely decrease the remaining carbon budget for $1.5^{\circ}$ C.npj Climate and Atmospheric Science 3, 1-7 (2020).

17. Huppmann, D., Rogelj, J., Kriegler, E., Krey, V.\& Riahi, K. A new scenario resource for integrated $1.5^{\circ} \mathrm{C}$ research. Nature Clim Change 8, 1027-1030 (2018).

18. Huppmann, D. et al. IAMC $1.5^{\circ} \mathrm{C}$ Scenario Explorer and Data hosted by IIASA. International Institute for Applied Systems Analysis \& Integrated Assessment Modeling Consortium. (2018) doi:10.22022/SR15/08-2018.15429. 
19. Meinshausen, M., Raper, S. C. B. \& Wigley, T. M. L. Emulating coupled atmosphereocean and carbon cycle models with a simpler model, MAGICC6 - Part 1: Model description and calibration. Atmospheric Chemistry and Physics 11, 1417-1456 (2011).

20. Meinshausen, M. et al. The shared socio-economic pathway (SSP) greenhouse gas concentrations and their extensions to 2500. Geosci. Model Dev. 13, 3571-3605 (2020).

21. Allen, M. R. et al. Warming caused by cumulative carbon emissions towards the trillionth tonne. Nature 458, 1163-1166 (2009).

22. Meinshausen, M. et al. Greenhouse-gas emission targets for limiting global warming to 2 ${ }^{\circ} \mathrm{C}$. Nature 458, 1158-1162 (2009).

23. Zickfeld, K., Eby, M., Matthews, H. D. \& Weaver, A. J. Setting cumulative emissions targets to reduce the risk of dangerous climate change. Proc Natl Acad Sci USA 106, 1612916134 (2009).

24. Gillett, N. P., Arora, V. K., Matthews, D. \& Allen, M. R. Constraining the Ratio of Global Warming to Cumulative $\mathrm{CO}_{2}$ Emissions Using CMIP5 Simulations. J. Climate 26, 6844-6858 (2013).

25. Collins, M. et al. Collins, M., R. Knutti, J. Arblaster, J.-L. Dufresne, T. Fichefet, P. Friedlingstein, X. Gao, W.J. Gutowski, T. Johns, G. Krinner, M. Shongwe, C. Tebaldi, A.J. Weaver and M. Wehner, 2013: Long-term Climate Change: Projections, Commitments and Irreversibility. In: Climate Change 2013: The Physical Science Basis. Contribution of Working Group I to the Fifth Assessment Report of the Intergovernmental Panel on Climate Change [Stocker, T.F., D. Qin, G.-K. Plattner, M. Tignor, S.K. Allen, J. Boschung, A. Nauels, Y. Xia, V. Bex and P.M. Midgley (eds.)]. Cambridge University Press, Cambridge, United Kingdom and New York, NY, USA. (2013).

26. Arora, V. K. et al. Carbon-concentration and carbon-climate feedbacks in CMIP6 models and their comparison to CMIP5 models. Biogeosciences 17, 4173-4222 (2020).

27. Jones, C. D. \& Friedlingstein, P. Quantifying process-level uncertainty contributions to TCRE and Carbon Budgets for meeting Paris Agreement climate targets. Environ. Res. Lett. 15, 074019 (2020).

28. Eyring, V. et al. Overview of the Coupled Model Intercomparison Project Phase 6 (CMIP6) experimental design and organization. Geoscientific Model Development 9, 19371958 (2016).

29. Taylor, K. E., Stouffer, R. J. \& Meehl, G. A. An Overview of CMIP5 and the Experiment Design. Bull. Amer. Meteor. Soc. 93, 485-498 (2011).

30. Tokarska, K. B. et al. Past warming trend constrains future warming in CMIP6 models. Sci. $A d v$ 6, eaaz9549 (2020).

31. Jiménez-de-la-Cuesta, D. \& Mauritsen, T. Emergent constraints on Earth's transient and equilibrium response to doubled $\mathrm{CO}_{2}$ from post-1970s global warming. Nat. Geosci. (2019).

32. Forster, P. M., Maycock, A. C., McKenna, C. M. \& Smith, C. J. Latest climate models confirm need for urgent mitigation. Nat. Clim. Chang. 10, 7-10 (2020).

33. Sutton, R. T. ESD Ideas: a simple proposal to improve the contribution of IPCC WGI to the assessment and communication of climate change risks. Earth Syst. Dynam. 9, 1155-1158 (2018).

34. IPCC, 2013. Summary for Policymakers. In: Climate Change 2013: The Physical Science Basis.Contribution of Working Group I to the Fifth Assessment Report of the Intergovernmental Panel on Climate Change [Stocker, T.F., D. Qin, G.-K. Plattner, M. Tignor, S.K. Allen, J. Boschung, A. Nauels, Y. Xia, V. Bex and P.M. Midgley 
(eds.)]. Cambridge University Press, Cambridge, United Kingdom and New York, NY, USA. (2013).

35. Knutti, R. \& Rogelj, J. The legacy of our $\mathrm{CO}_{2}$ emissions: a clash of scientific facts, politics and ethics. Climatic Change 133, 361-373 (2015).

36. IPCC AR5. Stocker, T. F., D. Qin, G.-K. Plattner, L. V. Alexander, S. K. Allen, N. L. Bindoff, F.-M. Bréon, J. A. Church, U. Cubasch, S. Emori, P. Forster, P. Friedlingstein, N. Gillett, J. M. Gregory, D. L. Hartmann, E. Jansen, B. Kirtman, R. Knutti, K. K. Kumar, P. Lemke, J. Marotzke, V. Masson-Delmotte, G. A. Meehl, I. I. Mokhov, S. Piao, V. Ramaswamy, D. Randall, M. Rhein, M. Rojas, C. Sabine, D. Shindell, L. D. Talley, D. G. Vaughan and S.-P. Xie (2013). Technical Summary. Climate Change 2013: The Physical Science Basis. Contribution of Working Group I to the Fifth Assessment Report of the Intergovernmental Panel on Climate Change. T. F. Stocker, D. Qin, G.-K. Plattner, M. Tignor, S.K. Allen, J. Boschung, A. Nauels, Y. Xia, V. Bex and P.M. Midgley. Cambridge, United Kingdom and New York, NY, USA, Cambridge University Press: 33-115. (2013).

37. Millar, R. J. et al. Emission budgets and pathways consistent with limiting warming to $1.5^{\circ} \mathrm{C}$. Nature Geoscience 10, 741-747 (2017).

38. Tokarska, K. B. \& Gillett, N. P. Cumulative carbon emissions budgets consistent with 1.5 ${ }^{\circ} \mathrm{C}$ global warming. Nature Climate Change 8, 296-299 (2018).

39. Jones, C. D. et al. The Zero Emissions Commitment Model Intercomparison Project (ZECMIP) contribution to C4MIP: quantifying committed climate changes following zero carbon emissions. Geosci. Model Dev. 12, 4375-4385 (2019).

40. MacDougall, A. H. et al. Is there warming in the pipeline? A multi-model analysis of the Zero Emissions Commitment from $\mathrm{CO}_{2}$. Biogeosciences 17, 2987-3016 (2020).

41. MacDougall, A. H., Zickfeld, K., Knutti, R. \& Matthews, H. D. Sensitivity of carbon budgets to permafrost carbon feedbacks and non- $\mathrm{CO}_{2}$ forcings. Environ. Res. Lett. 10, 125003 (2015).

42. Gasser, T. et al. Path-dependent reductions in $\mathrm{CO}_{2}$ emission budgets caused by permafrost carbon release. Nature Geoscience,11, 830-835 (2018).

43. Leduc, M., Matthews, H. D. \& de Elía, R. Quantifying the Limits of a Linear Temperature Response to Cumulative $\mathrm{CO}_{2}$ Emissions. J. Climate 28, 9955-9968 (2015).

44. Tokarska, K. B., Gillett, N. P., Weaver, A. J., Arora, V. K. \& Eby, M. The climate response to five trillion tonnes of carbon. Nature Climate Change 6, 851-855 (2016).

45. Hienola, A. et al. The impact of aerosol emissions on the $1.5^{\circ} \mathrm{C}$ pathways. Environ. Res. Lett. 13, 044011 (2018).

46. Lelieveld, J. et al. Effects of fossil fuel and total anthropogenic emission removal on public health and climate. Proc Natl Acad Sci USA 116, 7192-7197 (2019).

47. Forster, P. M. et al. Evaluating adjusted forcing and model spread for historical and future scenarios in the CMIP5 generation of climate models. Journal of Geophysical Research: Atmospheres 118, 1139-1150 (2013).

48. Grose, M. R., Gregory, J., Colman, R. \& Andrews, T. What Climate Sensitivity Index Is Most Useful for Projections? Geophysical Research Letters 45, 1559-1566 (2018).

49. Leduc, M., Matthews, H. D. \& de Elía, R. Regional estimates of the transient climate response to cumulative $\mathrm{CO}_{2}$ emissions. Nature Climate Change 6, 474 (2016).

50. Herrington, T. \& Zickfeld, K. Path independence of climate and carbon cycle response over a broad range of cumulative carbon emissions. Earth Syst. Dynam. 5, 409-422 (2014). 
51. Winton, M., Takahashi, K. \& Held, I. M. Importance of Ocean Heat Uptake Efficacy to Transient Climate Change. J. Climate 23, 2333-2344 (2010).

52. Armour, K. C., Bitz, C. M. \& Roe, G. H. Time-Varying Climate Sensitivity from Regional Feedbacks. J. Climate 26, 4518-4534 (2013).

53. Andrews, T. et al. Accounting for Changing Temperature Patterns Increases Historical Estimates of Climate Sensitivity. Geophysical Research Letters 45, 8490-8499 (2018).

54. Comyn-Platt, E. et al. Carbon budgets for 1.5 and $2{ }^{\circ} \mathrm{C}$ targets lowered by natural wetland and permafrost feedbacks. Nature Geoscience 11, 568-573 (2018).

55. Tokarska, K. B., Zickfeld, K. \& Rogelj, J. Path independence of carbon budgets when meeting a stringent global mean temperature target after an overshoot. Earth's Future 7, 1283-1295 (2019).

56. Frölicher, T. L. \& Paynter, D. J. Extending the relationship between global warming and cumulative carbon emissions to multi-millennial timescales. Environ. Res. Lett. 10, 075002 (2015).

57. Shindell, D. \& Smith, C. J. Climate and air-quality benefits of a realistic phase-out of fossil fuels. Nature 573, 408-411 (2019).

58. Rogelj, J. et al. Air-pollution emission ranges consistent with the representative concentration pathways. Nature Clim Change 4, 446-450 (2014).

59. Haustein, K. et al. A real-time Global Warming Index. Scientific Reports 7, 15417 (2017).

60. Rogelj, J., Schleussner, C.-F. \& Hare, W. Getting It Right Matters: Temperature Goal Interpretations in Geoscience Research. Geophysical Research Letters 44, 10,662-10,665 (2017).

61. UNFCC. UNFCC, 2015. FCCC/CP/2015/L.9/Rev.1: Adoption of the Paris Agreement (pp. 1-32). UNFCCC, Paris, France. (2015).

62. Allen, M. R. et al. Framing and Context. In: Global Warming of $1.5^{\circ} \mathrm{C}$. An IPCC Special Report on the impacts of global warming of $1.5^{\circ} \mathrm{C}$ above pre-industrial levels and related global greenhouse gas emission pathways, in the context of strengthening the global response to the threat of climate change, sustainable development, and efforts to eradicate poverty [Masson-Delmotte, V., P. Zhai, H.-O. Pörtner, D. Roberts, J. Skea, P.R. Shukla, A. Pirani, W. Moufouma-Okia, C. Péan, R. Pidcock, S. Connors, J.B.R. Matthews, Y. Chen, X. Zhou, M.I. Gomis, E. Lonnoy, T. Maycock, M. Tignor, and T. Waterfield (eds.)]. In Cambridge, United Kingdom and New York, NY, USA. (2018).

63. Hawkins, E. et al. Estimating Changes in Global Temperature since the Preindustrial Period. Bull. Amer. Meteor. Soc. 98, 1841-1856 (2017).

64. Schurer, A. P., Mann, M. E., Hawkins, E., Tett, S. F. B. \& Hegerl, G. C. Importance of the pre-industrial baseline for likelihood of exceeding Paris goals. Nature Climate Change 7, 563 (2017).

65. Richardson, M., Cowtan, K., Hawkins, E. \& Stolpe, M. B. Reconciled climate response estimates from climate models and the energy budget of Earth. Nature Climate Change 6, 931 (2016).

66. Schleussner, C.-F. et al. Science and policy characteristics of the Paris Agreement temperature goal. Nature Climate Change 6, 827-835 (2016).

67. Tokarska, K. B. et al. Uncertainty in carbon budget estimates due to internal climate variability. Environ. Res. Lett., 15, 104064 (2020). 
68. Morice, C. P., Kennedy, J. J., Rayner, N. A. \& Jones, P. D. Quantifying uncertainties in global and regional temperature change using an ensemble of observational estimates: The HadCRUT4 data set. Journal of Geophysical Research: Atmospheres 117, (2012).

69. Cowtan, K. Coverage bias in the HadCRUT4 temperatureseries and its impact on recent temperaturetrends. Update: COBE-SST2 based land-ocean dataset. Unpub (2017).

70. Cowtan, K. et al. Robust comparison of climate models with observations using blended land air and ocean sea surface temperatures. Geophysical Research Letters 42, 6526-6534 (2015).

71. Pfleiderer, P., Schleussner, C.-F., Mengel, M. \& Rogelj, J. Global mean temperature indicators linked to warming levels avoiding climate risks. Environ. Res. Lett. 13, 064015 (2018).

72. Schurer, A. et al. Estimating the Transient Climate Response from Observed Warming. Journal of Climate 31, 8645-8663 (2018).

73. Rogelj, J. et al. A new scenario logic for the Paris Agreement long-term temperature goal. Nature 573, 357-363 (2019).

74. Kumar, S. et al. Land use/cover change impacts in CMIP5 climate simulations: A new methodology and 21st century challenges. Journal of Geophysical Research: Atmospheres 118, 6337-6353 (2013).

75. Simmons, C. T. \& Matthews, H. D. Assessing the implications of human land-use change for the transient climate response to cumulative carbon emissions. Environ. Res. Lett. 11, 035001 (2016).

76. Lawrence, D. M. et al. The Land Use Model Intercomparison Project (LUMIP) contribution to CMIP6: rationale and experimental design. Geoscientific Model Development 9, 2973-2998 (2016).

77. Zickfeld, K., MacDougall, A. H. \& Matthews, H. D. On the proportionality between global temperature change and cumulative $\mathrm{CO}_{2}$ emissions during periods of net negative $\mathrm{CO} 2$ emissions. Environ. Res. Lett. 11, 055006 (2016).

78. Koven, C. D., Lawrence, D. M. \& Riley, W. J. Permafrost carbon-climate feedback is sensitive to deep soil carbon decomposability but not deep soil nitrogen dynamics. Proc Natl Acad Sci USA 112, 3752 (2015).

79. McGuire, A. D. et al. Dependence of the evolution of carbon dynamics in the northern permafrost region on the trajectory of climate change. Proc Natl Acad Sci USA 115 (15), 3882-3887 (2018).

80. Rogelj, J. et al. Understanding the origin of Paris Agreement emission uncertainties. Nat Commun 8, 15748 (2017).

81. United Nations Environment Programme. The emissions gap report 2019. (2019).

82. den Elzen, M., Janssen, M., Rotmans, J., Swart, R. \& Vries, B. Allocating constrained global carbon budgets: Inter-regional and inter-generational equity for a sustainable world. Int J Global Energy Issues 4, 287-301 (1992).

83. Robiou du Pont, Y., Jeffery, M. L., Gütschow, J., Christoff, P. \& Meinshausen, M. National contributions for decarbonizing the world economy in line with the G7 agreement. Environ. Res. Lett. 11, 054005 (2016).

84. Höhne, N., den Elzen, M. \& Escalante, D. Regional GHG reduction targets based on effort sharing: a comparison of studies. Climate Policy 14, 122-147 (2014). 
85. Gibson, R. B. et al. From Paris to Projects: Clarifying the implications of Canada's climate change mitigation commitments for the planning and assessment of projects and strategic undertakings. (University of Waterloo: Paris to Projects Research Initiative, 2019).

86. Crownshaw, T. et al. Over the horizon: Exploring the conditions of a post-growth world. The Anthropocene Review 6, 117-141 (2019).

87. Smith, C. J. et al. Current fossil fuel infrastructure does not yet commit us to $1.5^{\circ} \mathrm{C}$ warming. Nature Communications 10, 101 (2019).

88. Tong, D. et al. Committed emissions from existing energy infrastructure jeopardize 1.5 ${ }^{\circ} \mathrm{C}$ climate target. Nature 572, 373-377 (2019).

89. Matthews, H. D. Quantifying historical carbon and climate debts among nations. Nature Clim Change 6, 60-64 (2016).

90. Höhne, N., den Elzen, M. \& Escalante, D. Regional GHG reduction targets based on effort sharing: a comparison of studies. Climate Policy 14, 122-147 (2014).

91. McKinnon, C. Climate justice in a carbon budget. Climatic Change 133, 375-384 (2015).

92. Samson, J., Berteaux, D., McGill, B. J. \& Humphries, M. M. Geographic disparities and moral hazards in the predicted impacts of climate change on human populations. Global Ecology and Biogeography 20, 532-544 (2011).

93. Meinshausen, M. et al. National post-2020 greenhouse gas targets and diversity-aware leadership. Nature Climate Change 5, 1098 (2015).

94. Rogelj, J. et al. Mitigation choices impact carbon budget size compatible with low temperature goals. Environmental Research Letters 10, 075003 (2015).

95. Smith, P. et al. Biophysical and economic limits to negative $\mathrm{CO}_{2}$ emissions. Nature Climate Change 6, 42-50 (2016).

96. Fuss, S. et al. Negative emissions-Part 2: Costs, potentials and side effects. Environ. Res. Lett. 13, 063002 (2018).

97. Cao, L. \& Caldeira, K. Atmospheric carbon dioxide removal: long-term consequences and commitment. Environ. Res. Lett. 5, 024011 (2010).

98. Jones, C. D. et al. Simulating the Earth system response to negative emissions. Environmental Research Letters 11, 095012 (2016).

99. Tokarska, K. B. \& Zickfeld, K. The effectiveness of net negative carbon dioxide emissions in reversing anthropogenic climate change. Environ. Res. Lett. 10, 094013 (2015). 100. Nemet, G. F. et al. Negative emissions-Part 3: Innovation and upscaling. Environ. Res. Lett. 13, 063003 (2018).

101. Frölicher, T. L. \& Joos, F. Reversible and irreversible impacts of greenhouse gas emissions in multi-century projections with the NCAR global coupled carbon cycle-climate model. Clim Dyn 35, 1439-1459 (2010).

102. Mathesius, S., Hofmann, M., Caldeira, K. \& Schellnhuber, H. J. Long-term response of oceans to $\mathrm{CO}_{2}$ removal from the atmosphere. Nature Climate Change 5, 1107-1113 (2015). 